\title{
Fonts of Potential: Areas for Typographic Research in Political Communication
}

\author{
Thomas J Billard \\ Annenberg School for Communication \& Journalism, \\ University of Southern California \\ tbillard@usc.edu
}

September 14, 2016

\begin{abstract}
As the prevalence of digital technologies has increased, so too has the prevalence of graphically designed content. In particular, typography has emerged as an increasingly important tool for visual communication. In recent years, political actors have seized upon the expressive potential of typography to communicate their messages, to support their campaign efforts, and to establish viable brand identities. However, researchers have been slow to address the new role typography plays in the processes of political communication. Therefore, this article both synthesizes and proposes key areas for research on typography in political communication. Drawing on extant literature across the fields of design, communication, and political science, this article identifies the ways in which typography contributes to the communicative and organizational aims of political actors, demonstrates these contributions with examples from recent political campaigns, and concludes by pointing toward unanswered questions for future studies to address.
\end{abstract}

Keywords typography, political communication, campaigns, branding, graphic design

Cite as Billard, Thomas J. 2016. "Fonts of Potential: Areas for Typographic Research in Political Communication." International Journal of Communication 10: 4570-4592. 


\section{Introduction}

When then-Senator Barack Obama unveiled the sleek, professional $O$ logo designed by Sol Sender that would be the symbol of his campaign for the American presidency (Figure 1), journalists and commentators proclaimed a new age in branded politics. When his campaign materials later switched typefaces from Gill Sans and Perpetua to Gotham (Figure 2), another flurry of commentary praised Obama's choice of visual rhetoric. Indeed, Gotham became so central to the identity of the Obama campaign - and the Obama brand - that the campaign requested a serif version of the typeface from designers Jonathan Hoefler and Tobias Frere-Jones for the 2012 campaign (Hoefler, 2011). Other political office seekers quickly realized the power of typefaces and professional typographic design to communicate their identities as candidates. For example, the campaign of Obama's 2008 opponent, Senator John McCain, chose Optima (Figure 3), the typeface used on the Vietnam War memorial in Washington, DC - the memorial to the war of which McCain is a veteran. However, first clear evidence of Obama's impact on candidates' typography was seen in the 2010 midterm elections, in which most candidates eschewed the serifed book faces typically used in political campaign materials for geometric sans serifs and branded typographic logos (Berlow, 2010).

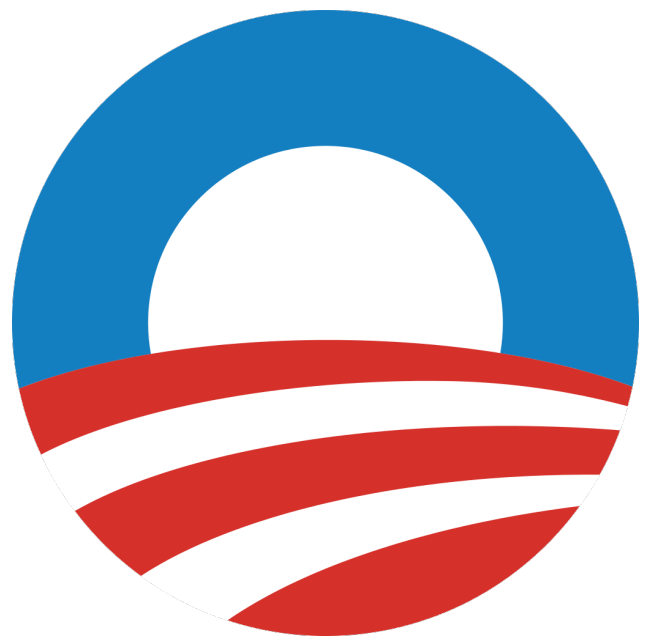

Figure 1: Barack Obama's campaign logo, designed by Sol Sender for the 2008 American presidential election.

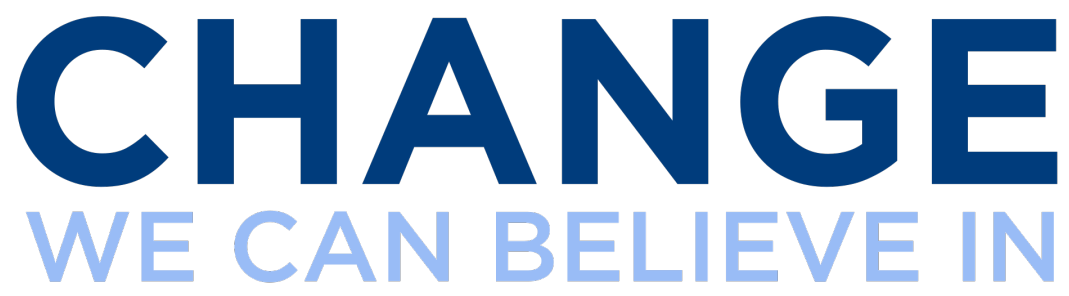

Figure 2: Barack Obama's "Change" banner set in Gotham, designed by John Slabyk and Scott Thomas. 


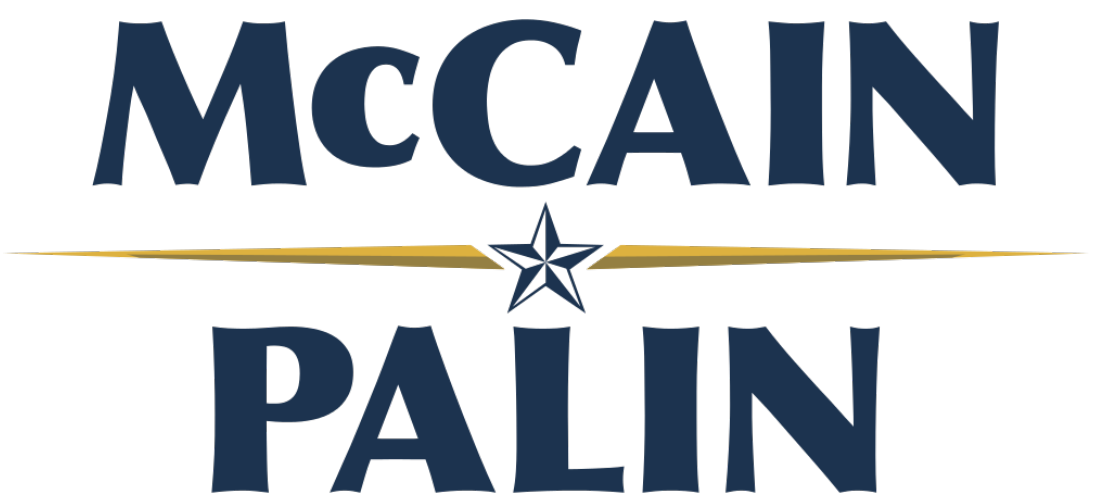

Figure 3: John McCain's campaign logo for the 2008 American presidential election, set in Optima.

In the 2016 presidential primary campaigns, candidates' typographic design has been a subject of great media attention (e.g., Strals \& Willen, 2015) - largely because of the campaigns' ambitious but failed attempts to create brand identities as resonant as Obama's. Marco Rubio's all-minuscule sans-serif logo, for example, was criticized for the odd choice to dot the $i$ in his name with a map of the continental United States and its poor kerning (Kurtzleben, 2015; see Figure 4). Jeb Bush's campaign likewise made strange typographic choices, opting to use his first name only, set in a bolded Baskerville, punctuated with an exclamation point (Figure 5). Even Hillary Clinton's logo, designed by esteemed designer and Pentagram partner Michael Bierut (and set in an arrow-adorned typeface amusingly referred to as "Hillvetica"), was criticized by both design experts and the Internet mobs for its poor color balance and uncanny resemblance to a hospital sign (see Haubursin, 2015; see Figure 6). Yet, despite the failures of most 2016 candidates' design choices, their clear prioritization of typographic design indicates that typography (among other elements of graphic design) has become increasingly important to the strategy of American political campaigns.

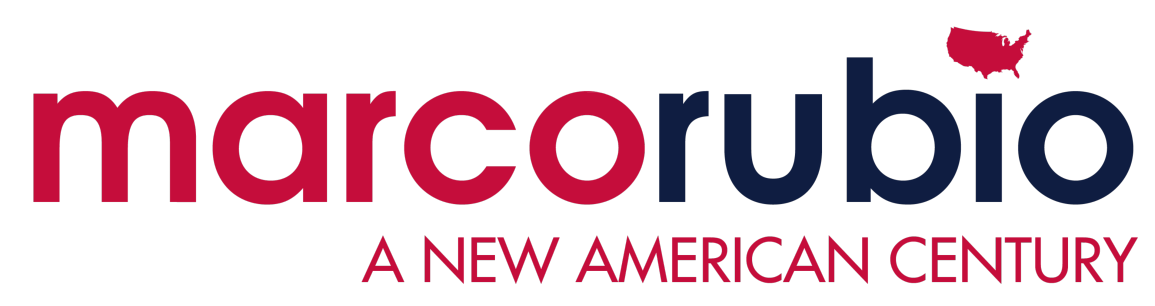

Figure 4: Marco Rubio's campaign logo for the 2016 American presidential election.

Attendant to the increasing significance of typography to American politics, scholars have begun directing attention to the role of typography in the branding of politics and the communication of political rhetoric and values. Yet, as Lupton (2001) notes, little theory pertaining to typography exists, largely because designers approach their work "more intuitively than intellectually" (p. 45; see also Crystal, 1998), and this is particularly true in the realm of political communication. Prior to the 


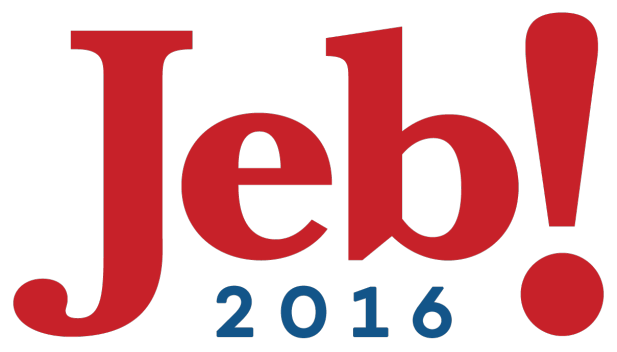

Figure 5: Jeb Bush's campaign logo for the 2016 American presidential election, set in Baskerville.

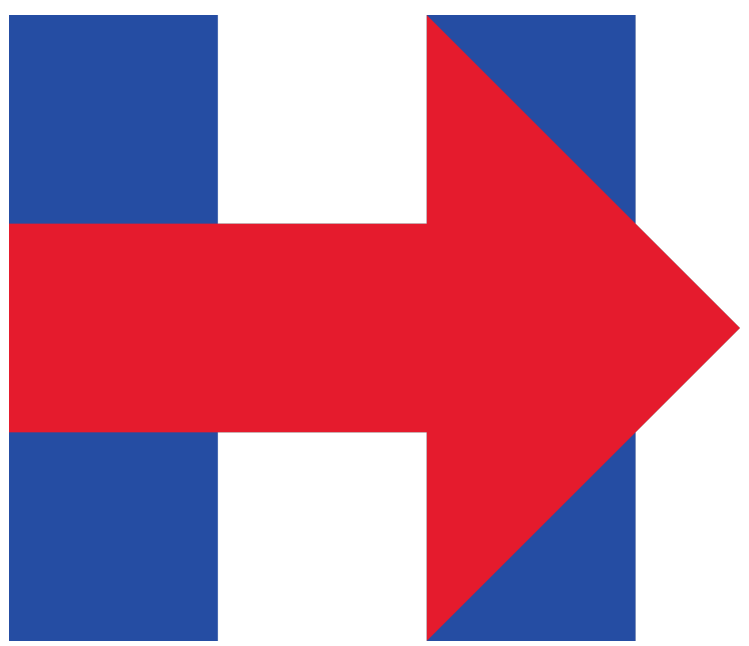

Figure 6: Hillary Clinton's campaign logo, designed by Michael Bierut for the 2016 American presidential election. 
first Obama campaign in 2008, the only studies of typography in political contexts investigated the ways in which ballot design contributed to the nonrecording of votes (Kimball \& Kropf, 2005). These studies focused primarily on issues of legibility, layout, and typographic features (Kimball \& Kropf, 2005; King Roth, 1994) and paid no attention to the communicative potential of typography. In large part the general inattention to typography can be explained by the fact that previous political campaigns only considered design in limited contexts, such as selecting typefaces for "bumper stickers and lawn signs" (Thomas, 2010, p. xxix). However, the new role of design in the 2008 Obama campaign piqued academic interest, inspiring several scholars to analyze the campaign's use of branding and graphic design (Ahmed, 2013; Banet-Weiser, 2012; Seidman, 2010; Zavattaro, 2010).

In this article I synthesize and propose key areas for research on typography in political communication, drawing on extant literature across the fields of design, communication, and political science. Moreover, I identify the ways in which typography contributes to the communicative and organizational aims of political actors, demonstrate these contributions with examples from recent political campaigns, and point toward unanswered questions for future studies to address. Before discussing the embodiment of national histories and political ideologies in typefaces, I review the growing literature on rhetoric, semiotics, and persuasion in typography. I then turn to the rise of branded politics in the United States, analyzing the role of typography in crafting candidate image and enhancing the visual communication of political advertising. Delving deeper into these areas, I analyze the role of typographic designers as political consultants in contemporary campaigns before finally moving to discuss how typography enables citizen participation in these campaigns. I then conclude by posing key questions for future inquiries into typography in political communication and calling for greater academic attention to this increasingly important topic.

\section{Rhetoric, Semiotics, and Persuasion in Typography}

Graphic design scholar Mara Gonzlez de Cosio (1998) defines rhetoric quite simply as the "art of communicating effectively and persuasively" (p. 265). Although the term certainly has much deeper implications in the realms of politics and philosophy, where it concerns typography and design, this definition succinctly summarizes what we might call rhetoric. Yet, we must also consider the individual nature of rhetoric. Fundamental to the creation and the success of rhetoric is the personality of the rhetor. In design, typeface stands in for authorial voice. As Beatrice Warde (1956) noted,

Set a page in Fournier against another in Caslon and another in Plantin, and it is as if you heard three different people delivering the same discourse - each with impeccable pronunciation and clarity, yet each through the medium of a different personality. ( $p$. 138)

In this way, Gotham became Obama's voice in his campaign, and the visual materials set in Gotham designed by the campaign (and by those participating unofficially in his campaign) became extensions of Obama's verbal rhetoric. ${ }^{1}$ Indeed, in her study of Gotham's suitability for Obama's campaign, Miriam Ahmed (2013) found that respondents identified Gotham as having the same rhetorical attributes as the textual messages of Obama's campaign advertisements.

The longest-running line of research on typographic meaning has been rhetorical. The earliest research of this kind was interested in identifying "atmospheres" (Ovink, 1938; Poffenberger \&

\footnotetext{
${ }^{1}$ This was, in fact, the intention of the Obama campaign. As campaign staff designer Scott Thomas (2010) has written, "We quickly discovered the full scope of our mission: to create a comprehensive visual message that would be a clear and direct visual translation of the candidate's rhetorical message" (p. xxviii).
} 
Franken, 1923) and "feeling tones" (Wendt, 1968); subsequent research used semantic qualities to identify typefaces' rhetorical personas (Bartram, 1982; Rowe, 1982). More recent research has more explicitly concerned itself with the visual rhetoric of typography, arguing that typefaces can alter the perception of how texts "sound" to readers (Brumberger, 2003a, 2003b; Kostelnick, 1990). Eva Brumberger (2003b) provides the clearest empirical evidence to date that typefaces have rhetorical impact, finding that readers attribute personality traits to different typefaces in a manner "analogous to verbal language" (p. 221).

However, little research in typographic rhetoric has addressed the individual features of typographic design. Rather, researchers have considered the typeface the base unit of analysis. Moreover, the extant rhetorical research considers typefaces as they might be presented in a uniformly typeset text (that is, as book faces), but not as they might be manipulated or combined in a typographically designed graphic, such as a logo or an advertisement. Here semioticians and linguists have stepped in to analyze how typography provides additional levels of meaning to written language (Crystal, 1998; Stckl, 2005; van Leeuwen, 2005, 2006). As David Crystal (1998) has written, to derive linguistic meaning from typography, we must "be able to identify those typographic features which are the source of the way a particular word, phrase, sentence, or text is to be interpreted" (Crystal, 1998, p. 10). According to this research, changes in typography cause "semantic change" that can either reinforce or alter the text's linguistic meaning (Crystal, 1998, p. 13). Theo van Leeuwen (2006) went so far as to argue that much of the meaning that was once held in "language is now realized, not through linguistic resource but through . . . typography" (p. 139). He further drew on notions of connotation and experiential metaphor to justify typography's consideration as a semiotic mode (van Leeuwen, 2005, 2006). As such, he argued, typography can "interpret" or "perform" text (van Leeuwen, 2006, p. 143). Thus, through analysis of a design's distinctive features (e.g., weight, expansion, slope, curvature, connectivity, orientation, regularity), one can identify the "semiotic potential" of typography to determine its visual meaning (van Leeuwen, 2006, p. 147).

Hartmut Stckl (2005) extended beyond surface-level analysis of the typeface as well, arguing that an additional level of meaning is communicated in the "pictorial qualities" (p. 206) of typographic design. In these designs, letterforms may represent "visual shapes which stand for objects from reality, signal states-of-affairs or actions, and illustrate emotions" (Stckl, 2005, p. 206). Moreover, the semiotic meaning of typography is decoded through tacit interpretation of both the visually connotative and the pictorial elements of the design, which activate existing mental images and their associated meanings (Stckl, 2005). Therefore, when typographically designed verbal messages are processed, the typopictorial meanings merge with the verbal meanings to create a holistic rhetorical message (Stckl, 2005).

Stckl's notion of typopictoriality is particularly generative for analyzing typographic design that goes beyond typesetting or the use of typefaces in a broader design, such as the manipulation of type in logos. Taking Obama's logo as an example, the geometric and evenly weighted $O$ represents his name - and thus him as a branded entity - but also represents the sun rising over a field of crops and the waving American flag (see also Seidman, 2010). Through the manipulation of simple shapes into a typopictorial design, and consequently the activation of existing mental associations, the Obama logo communicates the patriotism of the flag, prosperity of the harvest, and hope of dawn. Therein lies the difference in Obama's design and Hillary Clinton's Obama-inspired design. Though Clinton's logo resembles Obama's in its geometric and evenly weighted representation of her initial, it fails to deliver the same semiotic impact. Whereas Obama's logo had visual simplicity but semiotic complexity, Clinton's has visual simplicity and semiotic simplicity. Whereas Obama's logo communicated patriotism, prosperity, and hope simultaneously, Clinton's communicates only forward movement and continuity.

Although rhetoricians and semioticians have convincingly argued that typography communicates 
meaning visually, little research has explicitly investigated typography's persuasive abilities. In the context of advertising, McCarthy and Mothersbaugh (2002) argued that elements of typographic design persuade (i.e., influence perceptions and attitudes) through typographic outcomes, such as semantic associations. Recently, Errol Morris (2012) conducted a large experiment in the New York Times (with the help of David Dunning, professor of psychology at Cornell University) investigating the effect of typeface on message credibility. He found significantly different persuasion effects among the different typefaces, with Baskerville emerging as the most credible. Most interestingly, however, and though he does not note it, the typefaces cluster around design features. The three most credible typefaces are serif, the two next most credible are sans serif, and the least credible is the much loathed Comic Sans. Although the results of his study are questionable and their implications underexplored, they confirm the conventional wisdom accepted by designers and laypersons alike that typography influences attitudes toward the textual meaning it represents. As Brian Collins has said, speaking of the Obama campaign's choice of Gotham,

Put the word "change" in Comic Sans and the idea feels lightweight and silly. Place it in Times New Roman and it feels self-important. In Gotham, it feels just right. Inspiring, not threatening. In the end, typography makes a real difference when it delivers words and ideas that are relevant to people. And for many, that seems to be the case here. (quoted in Heller, 2010, p. xxiv)

\section{National History and Political Identity in Typography}

Much of typography's meaning, however, is determined by its historic uses (Kinross, 2004). Significant research has analyzed the political and ideological meanings of typography, which are most often determined by their relationship to national histories and traditions (Morison, 2001). As Otl Aicher remarked, "Writing systems are political, and typography is just as rich a source of cultural insight as gastronomy" (quoted in Shaw, 2001, p. 77). Jadette Lalibert (1987) identified several typefaces as having particular nationalist identities: Fraktur is German, Garamond is French, Bodoni is Italian, and Caslon is English (Figure 7). Fraktur has received particular attention in past scholarship because of its relationship to fascism, German nationalism, and the Third Reich (Garfield, 2010; Heller, 2001; Shaw, 2001; Willberg, 1998); however, typography continues to convey national identity and ideological meaning in modern times, and new typographic features evolve as nations and political environments do.

For example, though Caslon has been historically associated with English national identity, the 20th century saw a typographic turn toward a distinctly British national identity in the form of Gill Sans. When Gill Sans was first issued in 1928, it served as the display typeface for stations and timetables of British Rail, the company formed to unify the four main regional rail systems, to nationalize transit in the United Kingdom. In the 1990s, as British Rail gave way to the privatization of the railways, the British Broadcasting Corporation (BBC) selected Gill Sans as its house font. Then, in 2003, the British government adopted Gill Sans for all official communications, causing some to regard it as "Britain's house style" (Holmes, 2008, p. 48). As famed typeface designer Tobias Frere-Jones recently explained in an interview for the podcast Design Matters,

I could open the kitchen cabinet and immediately know what my mom had brought home from London and what came from the supermarket down the street . . . Eventually I figured out that it was something to do with the lettering. I mean, I tried experiments with turning all the jars around so I couldn't see the fronts of the labels, it was just [the] list of ingredients on the back - just those little blocks of text - and still just from that cue I could tell what was British and what was American. And I eventually figured out 


\section{(OSermany (כ્ealitux) France (Garamond) Italy (Bodoni) England (Caslon) Britain (Gill Sans) America (Gotham)}

Figure 7: Typefaces and their national identities.

that I was spotting Gill Sans, which was not showing up on anything American, and it was all over the British stuff. And that's the thing I was identifying. (Millman, 2015)

The national identity of typefaces is relatively innocuous in this context, but where the history of colonial rule is involved, typefaces become grounds for battles of visual cultures. Kurt Campbell (2013) has thoroughly analyzed the sociogenic implications of the use of Gill Sans mandated in South Africa's 2005 rebranding. This rebranding sought to establish a new visual identity for South Africa following the end of Apartheid that "reflects a unique history in addition to embracing the future" (Campbell, 2013, p. 72). Yet the choice to represent a unified South African identity with Gill Sans - the national typeface of South Africa's former colonial rulers, both officially in government and unofficially in culture - is to assert the continued valuation of the colonial culture over the native culture. Campbell (2013) further argued that the typefaces published in I-Jusi magazine and those designed by Jan Erasmus (particularly Thornface; see Figure 8) represent "alternative ways of thinking about the role of type in the national branding of South Africa" (p. 90) that more aptly visualize South African identity as inherently African and as a synthesis of intermingling cultural influences, rather than as submissive to British cultural power. These faces "embrace the inspirational heritage of various African alphabets and their shared ajami calligraphic traditions in constituting letters through creative agency and typographic syncretism that directly reference aspects of South Africa, its ecology and its society" (Campbell, 2013, p. 90). To the extent, then, that typefaces represent national identity and colonial power, they are inherently politically ideological.

No single typographic style has received more attention for its political ideology than German black letter (particularly Fraktur). The earliest association between German cultural identity and black letter originated from its association with Lutheranism, the distinctly German strain of Protestantism, and black letter soon became synonymous with the German language (Shaw, 2001). Following German unification in 1871, black letter's prominence surged at times when the new nation "struggled to define itself on the international stage" (Garfield, 2010, p. 190). Then, at the turn 


\section{SOUTH AFriCA ('THORNFACE)}

Figure 8: Thornface, designed by South African typeface designer Jan Erasmus.

of the 20th century, German typographers began to shift toward Roman type, with a particular eye toward legibility on the international market. However, this new typographic style was largely associated with Bolsheviks and Futurists, and the newly empowered Nazi government considered Roman type "degenerate" (Garfield, 2010, p. 191). Bauhaus designers Paul Renner (designer of Futura and Century Gothic) and Jan Tschichold (design theorist and author of Die neue Typographie) were even arrested by the Nazi government for their advocacy of Roman type (Garfield, 2010). In the words of Simon Garfield (2010), "Third Reich propaganda not only employed gothic lettering for its message, but made it the message itself: one slogan read ?Feel German, think German, speak German, be German, even in your script"' (p. 191). As a consequence, black letter continues to hold connotations of both German nationalism and fascistic conservatism (Heller, 2001; Shaw, 2001; Willberg, 1998).

Fascist ideology in Italy likewise had its own typographic style, an aesthetically moderate adaptation of Futurist style (Doordan, 1995, 1997). Like Futurism, Italian fascism promoted "technology, violence, danger, movement, and speed" (Carter, Meggs, Day, Maxa, \& Sanders, 2015, p. 112), which is evident in the typographic design of fascist propaganda. Dennis P. Doordan (1997) cited the example of Attilio Calzavara, a graphic designer often commissioned to design reports and other official materials for the Italian fascist regime. His cover of La Direttissima Bolgona-Firenze 1934XII (1934; see Figure 9), for instance, employs the bold, active, and expressive typography typical of Futurist style; the title of the document "race[s] across the page in dynamic motion" (Carter et al., 2015, p. 112).

Even absent associations with national identities, though, typography can communicate political ideology, particularly in relation to its attitudes toward labor and markets. As a prime example, Jan Tschichold's 1928 manual for designers, Die neue Typographie (The New Typography), is in essence a political manifesto, a manifesto for an inherently socialist design (see Tschichold, 1995). His ideals of typography encapsulate socialist ideology at every turn, from his espousal of a collective style with no personally distinguishable characteristics - a product of the anonymous laborer - to his emphasis on work and the means of production. Indeed, the entire creative output of the Bauhaus, of which Tschichold was a key figure, espoused these ideals and encoded them into their designs. ${ }^{2}$ This socialist functionality of the New Typography stood in strong opposition to the "handicraft idealism" of Stanley Morison, among others, whose style valued the very individualism and manual (rather than industrial) labor that Tschichold condemned (Sandusky, 2001; see also Kinross, 2014). Whereas Morison valued the "authenticity" of the craftsman's work and celebrated the artistry of the individual craftsman, Tschichold valued form adapted in the service of function (Sandusky, 2001). Furthermore, their respective ideologies informed the typography they designed and celebrated. While Morison oversaw the design of Times New Roman, an old-style serif typeface rooted in prenineteenth century printing traditions, Tschichold extolled the virtues of Paul Renner's Futura, an unadorned geometric sans-serif typeface with an industrial feel (Figure 10).

In many ways, Gotham can be said to trace its lineage to Futura: It is a geometric sans-serif typeface, the design of which was based on functional urban signage. Beyond the superficial, Gotham

\footnotetext{
${ }^{2}$ See Weingarden (1985) for a thorough review of the incorporation of socialist ideology in the work of the Bauhaus.
} 


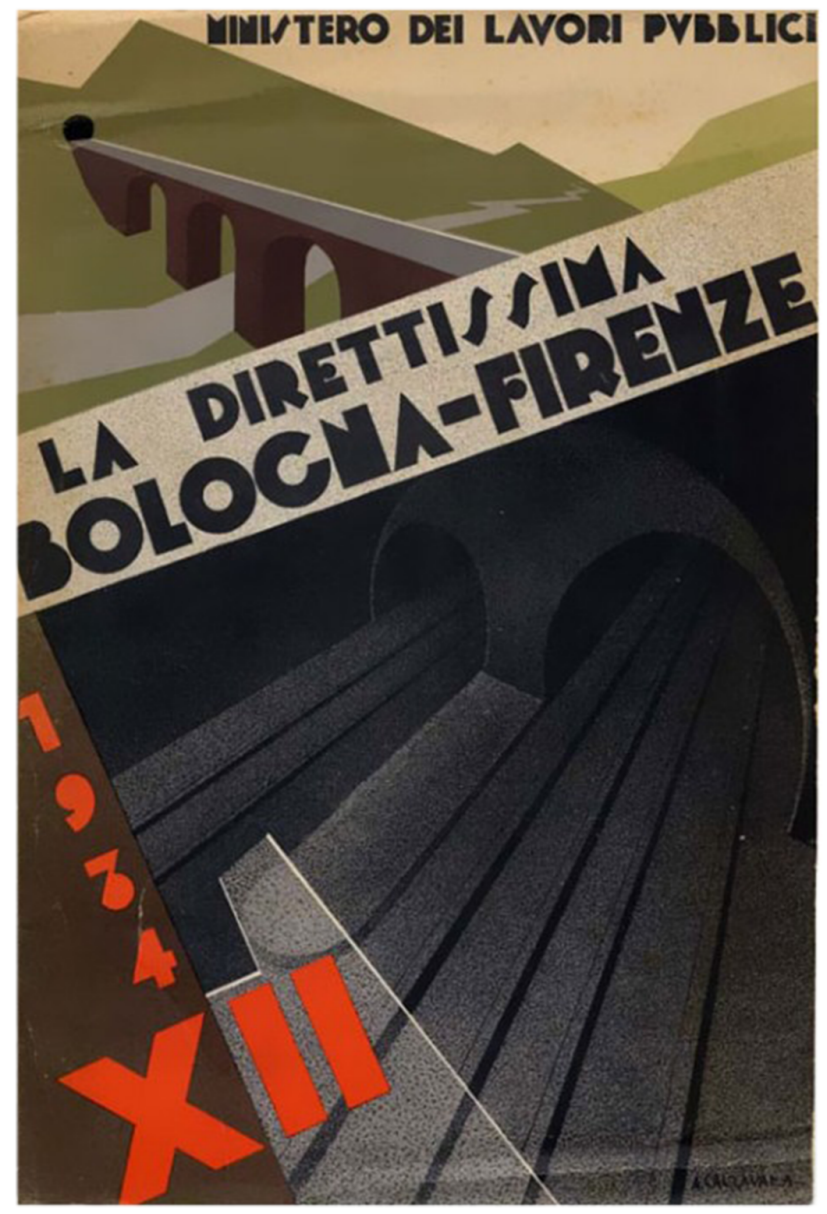

Figure 9: Cover of La Direttissima Bolgona-Firenze 1934-XII (1934), designed by Attilio Calzavara.

\section{Handicraft (TNR) Industrial (Futura)}

Figure 10: Times New Roman (representing Morison's "handicraft idealism" in typography) versus Futura (representing Tschichold's industrial-oriented socialist ideology in typography). 
also carries forward Futura's ideological orientation. The unadorned simplicity of the typeface renders it industrial, anonymous, and distinctly working class, reflecting the "unassuming" and "blue collar" environment of New York City's Port Authority Bus Terminal on which its design is based (Thomas, 2010, p. 99). In his book on the graphic design of Obama's 2008 campaign, campaign staff designer Scott Thomas referred to Gotham as the American typeface, which, given the progressive roots of its design, carries great implications. Recently, Waldeck (2014) argued that typefaces do not so much have national origins as they have been claimed by nations, in a sense as brand markers of imagined national traditions. In that sense, the choice of typeface says a lot about the vision for the country's future the candidate intends to communicate. For Obama's campaign to select Gotham, then, is to communicate a vision in which America is diverse, working class, and an anonymous participant in the social collective. Furthermore, that the campaign switched typefaces from Gill Sans and Perpetua, both designed by Eric Gill with clear British cultural referents, suggests a rejection of white Anglo-Saxon identity as the default brand of the nation, and rebrands American identity as ethnically diverse and, like the area surrounding the Port Authority, comprised largely of aspirational people of color.

\section{Branding Politics, Political Brands}

The increasing role of branding in American politics - as demonstrated by Obama's pseudocorporate logo and rhetorically motivated use of Gotham, and by other candidates' subsequent attempts to replicate his success - has been a subject of heightened scrutiny in recent years (e.g., Banet-Weiser, 2012; Seidman, 2010; Zavattaro, 2010). Cultural theorist Sarah Banet-Weiser (2012) has thoroughly analyzed how this increase has led to the commodification and consequent consumption of politics as a brand that defines the self. In her words, "politics is becoming a marketable commodity . . . expressed through brand designs, logos, symbols, and metaphors" (Banet-Weiser, 2012, p. 130-131; see also Zavattaro, 2010, p. 123). In the context of electoral politics, voting for a president thus becomes the purchase of a personal political identity and collective national identity.

The notion of candidates relying on symbols and metaphors is not new to the study of political communication, however. Political communication scholars Stephen Ansolabehere and Shanto Iyengar (1995) argued that political advertisements rely upon prevalent and easily understood cultural symbols and metaphors to persuade likely voters and the politically uninformed alike. Political advertisements have consequently received much criticism for their failure to inform voters on policy issues (see, e.g., Hollihan, 2009). Nonetheless, these advertisements "give [voters] confidence that they can decide between competing candidates on the basis of their character and suitability for elected office" (Hollihan, 2009, p. 155). Where the contemporary (typo)graphically designed campaign departs from traditional campaign advertising, though, is in its ability to communicate multilayered messages with more brevity. While the Obama logo followed the suit of past presidential logos in its use of patriotic colors, it also "expressed the campaign's themes - something that all [past candidates'] designs did not do" (Seidman, 2010, p. 7). That is to say, the Obama campaign's typographic design developed and represented a brand.

Generally speaking, typography contributes to the development of political brands in two key ways: by crafting candidate image visually, and by increasing the economy of expression in campaign advertisements.

\subsection{Branding and Candidate Image}

Political scientist Dan D. Nimmo (1974) defined image as "an interpreted sensation" or "a meaningful impression, appearance, semblance, or similar mental representation of our perceptions" (pp. 5-6). 
This image is developed as a sum total of "all past experience of the possessor of the image. Part of the image is the history of the image itself" (Hollihan, 2009, p. 75). Candidate image can thus be understood as a cultivated persona, a simplified synthesis of the history of both the individual candidate and past candidates with whom they wish to associate themselves and of cultural expectations of candidates. Likewise, typefaces are designed within the context of typographic history and broader visual culture, appropriating historical design features and reinterpreting them through contemporary cultural and technical conventions (Leonidas, 2012). Furthermore, in much the same way that campaign strategists focus on crafting strong political identities, the primary concern of most typeface designers is creating legible and aesthetically appealing typefaces that "convey strong identities" (Leonidas, 2012, p. 31).

Although candidate images are highly curated, contrary to many of the criticisms of branded politicians (e.g., Zavattaro, 2010), they often reflect the genuine personality of the candidate (Hollihan, 2009). Indeed, campaigns work hard to not fight candidates' preexisting images but to craft their image maintenance efforts around the public's perceptions (Hollihan, 2009). In designing candidates' visual identities, campaigns thus incorporate visual translations of candidates' public personas and personal philosophies into the design materials. Sol Sender, designer of Obama's $O$ logo, explained how he and his team adapted Obama's personality into their typographic designs:

When we received the assignment, we immediately read both of Senator Obama's books. We were struck by the ideas of hope, change, and a new perspective on red and blue (not red and blue states, but one country). . . . The design development was singularly inspired by the candidate's message. (quoted in Heller, 2010, p. xxv)

Campaign staff designer Scott Thomas (2010) has commented similarly that throughout the campaign process, typography was "used to incarnate . . . the candidate himself" (p. xxix).

Moving into the recent presidential primary, considering the high popularity of Obama's presidency, particularly among Democrats, Hillary Clinton has attempted to position herself as, in essence, a third Obama term. To achieve this, her campaign has crafted a similarly populist progressive image, including - and especially - visually. Her campaign has mimicked Obama's design aesthetics in both logo design and typeface selection, with modifications to suit her particular situation. For example, the Clinton campaign commissioned a custom typeface, deliberately named "Unity," a variation on Sharp Sans by Lucas Sharp. Like Gotham, Unity is a modern geometric sans-serif typeface. Yet, in the face of concerns over public perceptions of harshness and sexist perceptions of bossiness, Unity softens the features of Sharp Sans, replacing the square dots on $i$ 's and $j$ 's with circles and rounding off other features. Additionally, whereas Obama's designers almost exclusively used Gotham in all-majuscule, Clinton's designers only ever set materials in Unity in all-minuscule or sentence case to avoid activating negative stereotypes. Therefore, we can see the ways in which Clinton's campaign has activated voters' past experiences with Obama's typographic style, while also being careful to tailor the design in deference to their past experiences with her image and her individual personality.

\subsection{Branding and Political Advertising}

Closely related to, and often an influence on, candidate image is campaign advertisement. Campaign advertisements, according to political scientist Michael M. Franz (2011),

are designed to convey a simple, evocative message in short bursts (and with sometimes numbing repetition). Knowing nothing about the issues or the candidates does not preclude someone from reacting to a simple, compelling message about family, morals, the economy, or national security" (p. 127). 
In short, they require only vague understandings of ubiquitous cultural scripts and values. In this respect, the processing of campaign advertisements is similar to the processing of typographic meaning (Crystal, 1998; Stckl, 2005; van Leeuwen, 2005, 2006). Thus, the typographic design of a political advertisement must reflect the same cultural values as the verbal message of the advertisement. Technical communication researcher Eva R. Brumberger (2003a) has indeed demonstrated that the readers of a text are aware of the "appropriateness" of the text's typography to its verbal message and that incompatibility between the two is noticed. Furthermore, she noted in another study that typography, "much like the verbal language used, must hold the same connotations for both the writer and the reader" (Brumberger 2003b, p. 209; see also Kostelnick, 1990; Tannenbaum, Jacobson, \& Norris, 1964), highlighting the importance of relying on prevalent cultural symbols in political advertisements' typographic design.

There is reason to suspect that typography might play a particularly strong role in the advertising released early in the campaigns, as that is when perceptions of candidate image and message comprehension are most malleable. Communication scholars Michael Pfau and Roxanne Parrott (1993) have written that in the first stage of a campaign, the objective is to raise awareness of candidate identity and to demonstrate the candidate's platform. Political advertising plays a significant role in this process and is, in fact, much more impactful in the early stages of campaigns (Cundy, 1986; Hollihan, 2009). Particularly for relatively unknown candidates, political advertising at the onset of the campaign is likely crucial to the candidates' success. Typography's primary contribution to this objective is its economy of expression; through its references to national identities and political ideologies, and through its typopictoriality, typography can communicate complex and multilayered messages in a single moment. For example, the use of Gotham in Obama's political advertising introduced him to the public in such a way that he "somehow feels familiar" (Hoefler \& Frere-Jones, quoted in Ahmed, 2013, p. 10) despite having little name or brand recognition at the time. Furthermore, Gotham expressed Obama's message in "an honest tone that's assertive but never imposing, friendly but never folksy, confident but never aloof . . . [plainspoken] with a welcome sophistication" (Hoefler \& Frere-Jones, quoted in Ahmed, 2013, p. 10).

The Obama campaign's typographic design was noted for its innovative role in candidate branding, and so too was Obama's use of digital technologies (see Banet-Weiser, 2012). As digital technologies replace traditional media as most Americans' primary sources of information, campaigns are increasingly able to communicate messages directly to individuals (Haynes \& Pitts, 2009; Iyengar, 2016). Moreover, political scientists Audrey A. Haynes and Brian Pitts (2009) have demonstrated that in 2008, the presidential primary candidates who attracted the most individual traffic to their websites were also able to raise the most money through small contributions. Thus, the campaigns' direct communications to individual citizens increased the desired outcomes of the advertising (in this case, fundraising). And whereas the traditional means of political advertising - yard signs, televisions ads, direct mail, and newspaper ads (Hollihan, 2009) - have required design, digital media center design, particularly typographic design, to an extent that older media have not.

\section{Designers as Political Consultants}

A subject of great academic controversy has been the increasing role of political consultants in American election campaigns (Dulio, 2004, 2011; Hollihan, 2009; Sabato, 1981). Political scientist David A. Dulio (2004) has defined the term consultant as "an individual or firm that provides campaign services on a fee-for-service basis during an election cycle for more than one candidate, political party, organized interest group, or initiative and referendum campaign for more than one election cycle" (p. 44). A consultant's primary role is to identify and strategically emphasize the issues and identities that resonate with the public on which the client (the candidate) is stronger 
than the opponent(s) (Dulio, 2011). As such, the design teams hired by the Obama campaign qualify for consideration as political consultants, perhaps the first designers to qualify as such. Sol Sender and his team that designed Obama's logo were given full reign to brand Obama as they saw fit, trusted as professionals to create a resonant visual message (Seidman, 2010). John Slabyk and Scott Thomas, Obama's "new media designers," were likewise hired to direct Obama's visual messaging, but unlike Sender, they became full-time members of the Obama team until the end of the election cycle.

Although the use of professional designers throughout the campaign is a recent development, it is part of a larger trend of the professionalization of electoral campaigns, whereby skilled workers make a living practicing the art of "electioneering" (Dulio, 2011; Grossmann, 2009; Plasser, 2000). At the same time, the design profession has increasingly professionalized with the rise of design-only firms, rather than in-house designers working for firms in other industries. Campaign consulting and design have professionalized for the same reason: money. Although campaigns run by professional consultants raise more money than those run by "amateurs" (Dulio, 2011; see also Haynes \& Pitts, 2009), the rise of professionalization among designers can be attributed to "the increasing cost of time" (Horn, 1999, p. 17). Moreover, the number of consultants working for a campaign has a "significant and positive impact on share of the vote received by challenger and open-seat candidates" (Dulio, 2011, p. 261).

It is likely that the use of designers as consultants has had an impact on recent campaigns in this way, and will continue to have one in future campaigns. However, because the use of designers as political consultants is a recent development, most prominently traceable to Obama's 2008 campaign, it is difficult to assess the impact designers have on the campaigns. We can be sure, nonetheless, that there is a perception that they are influential, as candidates post-Obama have hired top-tier design professionals to work for their campaigns. For example, Hillary Clinton's campaign hired Michael Bierut and his team from Pentagram - which has redesigned, among others, Disney, Motorola, Benetton, the Library of Congress, and the New York Jets - to establish her visual brand.

Yet, despite the recognition from candidates that designers (might) play an important role as campaign consultants, academic attention to Obama's campaign consultants has ignored the design team. Recently, renowned political communication scholar Kathleen Hall Jamieson (2013) edited a print copy of a series of symposia on the role of campaign consultants in the 2012 Obama-Romney election. In the volume, Jim Margolis and Stuart Stevens, from Obama's and Romney's campaign staffs, respectively, discussed their candidates' branding only in passing. Margolis reported, "We actually formed within the campaign an Obama Media team" (Hall Jamieson, 2013, p. 129), though he did not mention that, unlike any previous campaign other than Obama's 2008 campaign, they had a dedicated full-time design team. Likewise, Stevens explained that the Romney campaign "put together teams of Madison Avenue and political people" and hired both an art director and a creative director (Hall Jamieson, 2013, p. 149), but nothing else was said of them or their work.

Rather, the only insight into the role the design team played in the Obama campaign comes from staff designer Scott Thomas's (2010) crowdfunded art book, Designing Obama: A Chronicle of Art \&3 Design from the 2008 Presidential Campaign. In it, Thomas provided valuable insights into the process of design, both typographic and nontypographic, and into the role the designers played in the daily running of the campaign. He discussed, for example, how early on there were no design experts in-house, only campaign staffers using (often improperly) the logo and then-official typeface of Gill Sans and Perpetua to create posters and other visual materials in word-processing programs. However, the campaign staff quickly realized the need for professional designers and established a design team to manage all visual communications created by the campaign. 


\section{Participation by Design}

In the final chapter of Designing Obama, Thomas (2010) presented a series of artistic and graphic works created by citizens inspired by Obama's campaign but otherwise disengaged from the process of electioneering. As he wrote, "Through design, we developed a relationship with our supporters that not only made our message meaningful, but also moved them to create statements of their own which were as powerful as any official campaign material" (Thomas, 2010, p. 149; see also Seidman, 2010). Beyond communicating with audiences and inspiring them to vote, the design of the Obama campaign engaged lay citizens in participatory politics, largely because of the "elasticity" of the design materials. In particular, the easy accessibility of Gotham, which so distinctly invoked Obama's brand, allowed citizens to create their own typographic design with very little effort. Designer Michael Bierut (2010) recounted such an instance:

At the height of the campaign, my daughter asked me if I could design a flyer for a friend's Obama benefit party at a little bar in Hoboken, New Jersey. We took the text and reset it in Gotham, downloaded the O logo, and put it together in minutes. "Wow," my daughter said. "It looks like Obama's actually going to be there!" Exactly. (p. xxi)

Though Seidman (2010) has described this quality of the Obama campaign's typographic design as viral, it would be more appropriately described as spreadable. Whereas virality evokes biological illness, implying passive (that is, nontransformative) and short-term transmission, spreadability implies active participation of media consumers as they transform and redistribute media in such a way that they add value to the message (Jenkins, Ford, \& Green, 2013; see also Jenkins, Ito, \& boyd, 2016). Indeed, citizen creators of graphic messages mimicking the Obama campaign's typography "used the logo unofficially, changing it to express their own sentiments" (Seidman, 2010, p. 6) and used Gotham on materials not created by the campaign to seamlessly add their voices to the official Obama rhetoric (Ahmed, 2013). This represents a new evolution of what Bennett (2004; Bennett \& Lagos, 2007) called "logo logic," or the attachment of political messages to preexisting brands through memetic manipulation and distribution through both digital and mainstream media platforms. Whereas he considered logo logic only in the context of anticorporate activism, parodying lifestyle brands to earn media attention and to ultimately position the activists in conversation with the targeted corporation, citizen participation in the Obama campaign through spreading usergenerated designs achieved much the same effect, but in a supportive rather than an antagonistic way.

What made the Obama campaign's typography so spreadable was the flexibility of the design. The Obama logo was designed specifically to permit the creation of "specialized logos," riffs on the original design that "integrated symbolic forms that signified a demographic's distinct qualities into the visual centerpiece of the logo" (Thomas, 2010, p. 15). Seidman (2010) cited the example of the logo variation on the women's issues page of Obama's website, which added a cross beneath the $O$ to form the female symbol. Thomas (2010) reproduces dozens of variations, from Obama Pride, which presents the $O$ logo with a rainbow wave of colors in place of the original red, to Beards for Obama, which presents the logo with a gray beard in place of the red.

Once the campaign began receiving masses of e-mails requesting image files of the logo and "Change" banner, the campaign made the uncommon choice to make all designed materials available online. As Thomas (2010) explained, "this open-source approach was a total shift away from traditional thinking about visual branding, in which proper brand management means centralized brand control" (p. 47), but the choice ultimately enabled heightened interaction with the campaign and a more grassroots approach to voter engagement. Thus, the choice to enable, if not encourage, unauthorized citizen participation in the Obama campaign's typographic design ran counter to corporate logics of brand management, but it might prove to define the logics of digital campaigning, 
particularly as subsequent electoral campaigns have attempted to replicate the successes of Obama's campaign.

\section{Conclusion: Toward the Future}

In this article I have traced several lines of inquiry pertaining to typographic meaning and strategic typographic design in political contexts. Yet what is perhaps most evident following this review is not any key assertions of the literature or trends in research but the dearth of academic inquiry and theoretical development in this area. Whereas the areas of rhetoric and semiotics in typography have enjoyed considerable attention (e.g., Ahmed, 2013; Bartram, 1982; Brumberger, 2003a, 2003b; Kostelnick, 1990; Rowe, 1982; Stckl, 2005; van Leeuwen, 2005, 2006), as have critical analyses of national identities and political ideologies in typography (e.g., Campbell, 2013; Garfield, 2010; Holmes, 2008; Kinross, 2014; Lalibert, 1987; Waldeck, 2014), the study of typography in contemporary political processes such as campaigns, advertising, and citizen engagement is only just beginning to emerge (Ahmed, 2013; Seidman, 2010). However, as the importance of typographic design to the political process continues to increase, further academic inquiries are certain to follow. To conclude, I thus identify several key lines of inquiry for future studies to address.

First, future research should draw together literature on the outcomes of typographic features of text (e.g., Lonsdale, 2014) and persuasion in political psychology (e.g., Nelson \& Garst, 2005) to interrogate the assumptions of critical research that asserts the persuasive power of typography. Moreover, future studies could investigate the influence of individual typographic features on perceptions of meaning, credibility, authority, and other rhetorical outcomes other than the vague "persona" that past studies have investigated (Brumberger, 2003a, 2003b).

Second, future studies should research the manifestation of political ideologies in the typographic designs of election candidates and political parties. An interesting study could trace trends in typography by conservative and liberal politicians over time, investigating how ideological differences manifest in design, and the relationships of these partisan aesthetics to historical contextual factors in their campaigns. Further studies could trace the diffusion of typographic innovations in advertising and politics, illuminating both the relationship between the advertising and electioneering industries and between campaigns for national and local offices.

Third, no research to my knowledge has yet explicitly addressed how typography is used in the process of crafting candidate images. Likewise, no research has yet addressed how typographic designers encode meaning in the campaign advertising materials they create. Ethnographic and qualitative interview studies could shed light on the creative processes of designers and on the processes of negotiation among the various actors in brand management surrounding the encoding of meaning in the design of visual campaign materials. Related, research on the role of consultants in political campaigns should extend to include the new role of typographers in political campaigns since the professionalization of campaign design.

Finally, researchers should further investigate the ways in which the emphasis on logo branding and typographic design in campaigns permits citizens to participate in the political process. A wealth of research has discussed the immense increase in opportunities for "participatory politics" (see Jenkins, Ito, \& boyd, 2016, Chapter 6, for an overview) and the role of digital media in political campaigns (see Heaney, Newman, \& Sylvester, 2011, for an overview), but little work has addressed the role typography, among other elements of graphic design, plays in enabling such participation. Considering the Internet's role as a participatory medium (Jenkins, Ford, \& Green, 2013; see also Jenkins, Ito, \& boyd, 2016), the great significance of graphic design to the use and organization of the Internet (Engholm, 2002), and the increasing power of the Internet to mobilize supporters (Haynes \& Pitts, 2009), future studies should take a participatory culture approach to understanding the 
role of graphic design in developing engaged communities around political office seekers and parties. 


\section{References}

Ahmed, M. M. (2013). Typeface persona: Investigating Gotham's suitability for Obama's 2008 presidential campaign (Unpublished doctoral dissertation). Howard University, Washington, DC.

Ansolabehere, S., \& Iyengar, S. (1995). Going negative: How political advertising shrinks and polarizes the electorate. New York, NY: Free Press.

Banet-Weiser, S. (2012). Authentic ${ }^{T M}$ : The politics of ambivalence in a brand culture. New York: New York University Press.

Bartram, D. (1982). The perception of semantic quality in type: Differences between designers and non-designers. Information Design Journal, 3(1), 38-50.

Bennett, W. L. (2004). Branded political communication: Lifestyle politics, logo campaigns, and the rise of global citizenship. In M. Micheletti, A. Follesdal, \& D. Stolle (Eds.), Politics, products, and markets: Exploring political consumerism past and present (pp. 101-125). New Brunswick, NJ: Transaction Books.

Bennett, W. L., \& Lagos, T. (2007). Logo logic: The ups and downs of branded political communication. Annals of the American Academy of Political and Social Science, 611, 193-206.

Berlow, S. (2010, November 2). 2010 election typography. Font Bureau. Retrieved from http://www.fontbureau.com/blog/2010-election-typography/

Bierut, M. (2010). Foreword. In S. Thomas, Designing Obama: A chronicle of art $\& 3$ design from the 2008 presidential campaign (p. xxi). Chicago, IL: Post Press.

Brumberger, E. R. (2003a). The rhetoric of typography: The awareness and impact of typeface appropriateness. Technical Communication, 50(2), 224-231.

Brumberger, E. R. (2003b). The rhetoric of typography: The persona of typeface and text. Technical Communication, 50(2), 206-223.

Campbell, K. (2013). The sociogenic imperative of typography: A "face" for the new South Africa. European Journal of English Studies, 17(1), 72-91.

Carter, R., Meggs, P. B., Day, B., Maxa, S., \& Sanders, M. (2015). Typographic design: Form and communication (6th ed.). Hoboken, NJ: Wiley.

Crystal, D. (1998). Towards a typographical linguistics. Type, 2(1), 7-23.

Cundy, D. T. (1986). Political commercials and candidate image. In L. L. Kaid, D. Nimmo, \& K. R. Sanders (Eds.), New perspectives on political advertising (pp. 210-247). Carbondale: Southern Illinois University Press.

Doordan, D. P. (1995). Political things: Design in fascist Italy. In W. Kaplan (Ed.), Designing modernity: The arts of reform and persuasion, 1885-1945 (pp. 225-255). New York, NY: Thames and Hudson.

Doordan, D. P. (1997). In the shadow of the fasces: Political design in fascist Italy. Design Issues, 13(1), 1885-1945.

Dulio, D. A. (2004). For better or worse? How political consultants are changing elections in America. Albany, NY: State University of New York Press.

Dulio, D. A. (2011). The impact of political consultants. In S. C. Craig \& D. B. Hill (Eds.), The electoral challenge: Theory meets practice (2nd ed., pp. 243-270). Washington, DC: CQ Press.

Engholm, I. (2002). Digital style history: The development of graphic design on the Internet. Digital Creativity, 13(4), 193-211.

Franz, M. M. (2011). Political advertising. In S. C. Craig \& D. B. Hill (Eds.), The electoral challenge: Theory meets practice (2nd ed., pp. 117-143). Washington, DC: CQ Press.

Garfield, S. (2010). Just my type: A book about fonts. London, UK: Profile Books.

Gonzlez de Cosio, M. (1998). Rhetoric in logotypes. Visible Language, 32(3), 264-279. 
Grossmann, M. (2009). Going pro? Political campaign consulting and the professional model. Journal of Political Marketing, 8(2), 81-104.

Hall Jamieson, K. (Ed.). (2013). Electing the president, 2012: The insiders' view. Philadelphia: University of Pennsylvania Press.

Haubursin, C. (2015, April 13). Designers explain why nobody likes Hillary Clinton's campaign logo. Vox. Retrieved from http://www.vox.com/2015/4/13/8406265/theres-a-reason-nobodylikes-hillary-clintons-campaign-logo

Haynes, A. A., \& Pitts, B. (2009). Making an impression: New media in the 2008 presidential nomination campaigns. PS: Political Science and Politics, 42(1), 53-58.

Heaney, M. T., Newman, M. E., \& Sylvester, D. E. (2011). Campaigning in the Internet age. In S. C. Craig \& D. B. Hill (Eds.), The electoral challenge: Theory meets practice (2nd ed., pp. 165-193). Washington, DC: CQ Press.

Heller, S. (2001). Designing hate: Is there a graphic language of vile emotion? In S. Heller \& P. B. Meggs (Eds.), Texts on type: Critical writings on typography (pp. 42-44). New York, NY: Allworth Press.

Heller, S. (2010). Foreword. In S. Thomas, Designing Obama: A chronicle of art $\mathcal{E}$ design from the 2008 presidential campaign (p. xxiii-xxv). Chicago, IL: Post Press.

Hoefler, J. (2011, April 4). Can we add serifs to Gotham? [Web log post]. Retrieved from http://www.typography.com/blog/can-we-add-serifs-to-gotham

Hollihan, T. A. (2009). Uncivil wars: Political campaigns in a media age (2nd ed.). Boston, MA: Bedford/St. Martin's.

Holmes, N. (2008). Eric Gill: Cut in stone. Visual Communication Quarterly, 15(1), 44-49.

Horn, R. E. (1999). Information design: The emergence of a new profession. In R. Jacobson (Ed.), Information design (pp. 15-33). Cambridge, MA: MIT Press.

Iyengar, S. (2016). Media politics: A citizen's guide (3rd ed.). New York, NY: Norton.

Jenkins, H., Ford, S., \& Green, J. (2013). Spreadable media: Creating value and meaning in a networked culture. New York: New York University Press.

Jenkins, H., Ito, M., \& boyd, d. (2016). Participatory culture in a networked era: A conversation on youth, learning, commerce, and politics. Cambridge, UK: Polity Press.

Kimball, D. C., \& Kropf, M. (2005). Ballot design and unrecorded votes on paper-based ballots. Public Opinion Quarterly, 69(4), 508-529.

King Roth, S. (1994). The unconsidered ballot: How design effects voting behavior. Visible Language $28(1), 48-67$.

Kinross, R. (2004). Modern typography: An essay in critical history (2nd ed.). London, UK: Hyphen Press.

Kostelnick, C. (1990). The rhetoric of text design in professional communication. Technical Writing Teacher, 17(3), 189-202.

Kurtzleben, D. (2015, April 14). Rubio's odd-looking campaign logo is teaching us an important lesson about typography. Vox. Retrieved from http://www.vox.com/2015/4/14/8411801/rubios-odd-looking-campaign-logo-is-teaching-us-an-important-lesson

Lalibert, J. (1987). La typographie moderne: Consequence de la revolution industrielle? [Modern typography: Consequence of the Industrial Revolution?]. Communication et Languages, 72(1), 60-76.

Leonidas, G. (2012). Type design and development. In Typography, referenced: A comprehensive visual guide to the language, history, and practice of typography (pp. 31-51). Beverly, MA: Rockport.

Lonsdale, M. (2014). Typographic features of text: Outcomes from research and practice. Visible Language, 48(3), 28-67. 
Lupton, E. (2001). A post-mortem on deconstruction? In S. Heller \& P. B. Meggs (Eds.), Texts on type: Critical writings on typography (pp. 45-47). New York, NY: Allworth Press.

McCarthy, M. S., \& Mothersbaugh, D. L. (2002). Effects of typographic factors in advertising-based persuasion: A general model and initial empirical tests. Psychology 83 Marketing, 19(7/8), 663-691.

Millman, D. (2015, December 7). Tobias Frere-Jones. Design Matters [Audio podcast]. Retrieved from http://designobserver.com/topic/designmatters/1039

Morison, S. (2001). First principles of typography. In S. Heller \& P. B. Meggs (Eds.), Texts on type: Critical writings on typography (pp. 170-177). New York, NY: Allworth Press.

Morris, E. (2012, August 8). Hear, all ye people; Hearken, O Earth (part 1). New York Times. Retrieved from http://opinionator.blogs.nytimes.com/2012/08/08/hear-all-ye-people-hearken-o-earth/

Nelson, T. E., \& Garst, J. (2005). Values-based political messages and persuasion: Relationships among speaker, recipient, and evoked values. Political Psychology, 26(4), 489-516.

Nimmo, D. D. (1974). Popular images of politics: A taxonomy. Englewood Cliffs, NJ: Prentice-Hall.

Ovink, G. W. (1938). Legibility, atmosphere-value, and forms of printing types. Leiden, NL: AW Sijthoff.

Pfau, M., \& Parrott, R. (1993). Persuasive communication campaigns. Needham Heights, MA: Allyn \& Bacon.

Plasser, F. (2000). American campaign techniques worldwide. Harvard International Journal of Press/Politics, 5(4), 33-54.

Poffenberger, A. T., \& Franken, R. B. (1923). A study of the appropriateness of type faces. Journal of Applied Psychology, 7(4), 312-329.

Rowe, C. L. (1982). The connotative dimension of selected display typefaces. Information Design Journal, 3(1), 30-37.

Sabato, L. J. (1981). The rise of political consultants: New ways of winning elections. New York, NY: Basic Books.

Sandusky, L. (2001). The Bauhaus tradition and the new typography. In S. Heller \& P. B. Meggs (Eds.), Texts on type: Critical writings on typography (pp. 129-138). New York, NY: Allworth Press.

Seidman, S. A. (2010). Barack Obama's 2008 campaign for the U.S. presidency and visual design. Journal of Visual Literacy, 29(1), 1-27.

Shaw, P. (2001). Lead soldiers. In S. Heller \& P. B. Meggs (Eds.), Texts on type: Critical writings on typography (pp. 77-81). New York, NY: Allworth Press.

Stckl, H. (2005). Typography: Body and dress of a text - a signing mode between language and image. Visual Communication, 4(2), 204-214.

Strals, N., \& Willen, B. (2015, July 31). Which 2016 presidential candidate has the worst logo? Washington Post. Retrieved from http://www.washingtonpost.com/posteverything/wp/2015/ 07/31/which-2016-presidential-candidate-has-the-worst-logo/

Tannenbaum, P. H., Jacobson, H. K., \& Norris, E. L. (1964). An experimental investigation of typeface connotations. Journalism Quarterly, 41(1), 65-73.

Thomas, S. (2010). Designing Obama: A chronicle of art $\&$ design from the 2008 presidential campaign. Chicago, IL: Post Press.

Tschichold, J. (1995). The new typography: A handbook for modern designers (R. McLean, Trans.). Berkeley: University of California Press.

van Leeuwen, T. (2005). Typographic meaning. Visual Communication, 4(2), 137-143.

van Leeuwen, T. (2006). Towards a semiotics of typography. Information Design Journal + Document Design, $14(2), 139-155$. 
Waldeck, M. (2014). Typography and national identity. In Proceedings from ICDHS 2014: The Ninth Conference of the International Committee for Design History and Design Studies (pp. 183-188). So Paulo, Brazil: Blucher.

Warde, B. (1956). On the choice of typefaces. In H. Jacob (Ed.), The crystal goblet: Sixteen essays on typography (pp. 137-149). Cleveland, OH: World Publishing Company.

Weingarden, L. (1985). Aesthetics politicized: William Morris to the Bauhaus. Journal of Architectural Education, 38(3), 8-13.

Wendt, D. (1968). Semantic differentials of typefaces as a method of congeniality research. Journal of Typographic Research, 2(1), 3-25.

Willberg, H. P. (1998). Fraktur and nationalism. In P. Bain \& P. Shaw (Eds.), Blackletter: Type and national identity (pp. 40-49). New York, NY: Princeton Architectural Press.

Zavattaro, S. M. (2010). Brand Obama: The implications of a branded president. Administrative Theory \& Praxis, 32(1), 123-128. 